\title{
Treatment of Class II division 1 malocclusion in a patient with traumatized central incisors: A case report
}

\section{Tratamento de maloclusão Classe II divisão 1 em um paciente com incisivos centrais traumatizados: relato de caso}

\begin{abstract}
Purpose: The objective of this paper is to report the clinical case of a patient with a Class II division 1 malocclusion with traumatized central incisors and the treatment option of extracting them, followed by space closure with lateral incisors replacement.

Case description: A female patient aged 10 years old reported a previous facial trauma due to a bike accident resulting in avulsion and reimplantation of both central incisors when she was 9 years old. The treatment plan included extraction of central incisors, pulling the lateral incisors to the central incisor position and restoring them to improve esthetics.

Conclusions: Extraction of maxillary central incisors is not a usual treatment protocol. However, for patients with traumatized central incisors with internal and external root reabsorption and Class II division 1 malocclusion it might be a good alternative for correction of the increased overjet.
\end{abstract}

Key words: Dental trauma; orthodontic treatment; tooth avulsion

\section{Resumo}

Objetivo: O objetivo deste trabalho é relatar o caso clínico de uma paciente portadora de maloclusão Classe II divisão 1 com incisivos centrais superiores traumatizados com reabsorção interna e externa e a opção de tratamento de extraí-los, seguido de fechamento do espaço com a mesialização dos incisivos laterais superiores.

Descrição do caso: Paciente do sexo feminino com 10 anos de idade relatou trauma facial, após queda de bicicleta, e avulsão e reimplante dos incisivos centrais superiores aos 9 anos de idade. Optou-se pela extração dos incisivos centrais superiores mesializando os incisivos laterais para a posição dos centrais, restaurando-os para ficar esteticamente aceitável.

Conclusão: A extração dos incisivos centrais superiores não é um protocolo de tratamento comum. Porém, para pacientes portadores de maloclusão Classe II divisão 1 com incisivos centrais traumatizados e com reabsorção radicular externa e interna pode ser uma boa solução para a correção do sobrepasse aumentado.

Palavras chave: Trauma dental; tratamento ortodôntico; avulsão dental

\author{
Telmo Bandeira Berthold a,d \\ Roger Corrêa de Barros Berthold b \\ Claiton Heitz ${ }^{c}$ \\ Rosana Kalaoun b
}

\begin{abstract}
- Department of Orthodontics, Pontifical Catholic University of Rio Grande do Sul, Porto Alegre, RS, Brazil

b Graduate Program in Dentistry / Oral and Maxillofacial Surgery, Pontifical Catholic University of Rio Grande do Sul, Porto Alegre, RS, Brazil

c Department of Oral and Maxillofacial Surgery, Pontifical Catholic University of Rio Grande do Sul, Porto Alegre, RS, Brazil

d Department of Orthodontics, Federal University of Rio Grande do Sul, Porto Alegre, RS, Brazil
\end{abstract}

\author{
Correspondence: \\ Telmo B. Berthold \\ Pontifical Catholic University of Rio Grande do Sul \\ (PUCRS) \\ School of Dentistry \\ Av. Ipiranga 6681 - Building 6 \\ Porto Alegre, RS - Brazil \\ 90616-900 \\ E-mail: tberthold@via-rs.net \\ Received: July 21, 2012 \\ Accepted: September 28, 2012 \\ Conflict of Interests: The authors state that there \\ are no financial and personal conflicts of interest that \\ could have inappropriately influenced their work. \\ Copyright: (c) 2012 Berthold et al.; licensee \\ EDIPUCRS. This is an Open Access article distributed \\ under the terms of the Creative Commons Attribution- \\ Noncommercial-No Derivative Works 3.0 Unported \\ License.
}




\section{Introduction}

Dental avulsion injuries are mostly seen in young patients in the anterior region of the maxilla (1). The main physical characteristics outlined as significant risk factors for dentoalveolar trauma are poor lip coverage and an increased overjet, which are both present in Class II division 1 malocclusion (2). If teeth are reimplanted there is a serious risk for permanent ankylosis and internal and/or external root resorption (3). Ankylosis of the central incisors is a challenge for any orthodontist.

In cases of Class II division 1 malocclusion with traumatized and ankylosed central incisors, extraction and space closure might be a solution to treat the increased overjet. However, this treatment option requires the lateral incisors to assume the role of central incisors and the canines to assume the role of the lateral incisors. The first premolars take the place of the canines, doing the excursive movements with restorative treatment for camouflage the positional changes. Therefore, the objective of this article was to demonstrate this procedure in a young patient.

\section{Case description}

A female patient aged 10 years old sought orthodontic treatment at a private clinic in Porto Alegre, RS, Brazil. Her chief complaint was poor esthetics and incisor protrusion. She and her parents reported a previous facial trauma due to a bike accident with avulsion and reimplantation of both central incisors when she was 9 years old. The patient and her parents did not recall the real conditions and procedure of the teeth reimplantation.

The clinical examination showed both central incisors with color change of the crowns (Fig. 1). The left central incisor was extensively restored due to crown fracture in the trauma episode. The radiographs showed both central incisors with internal and external root resorption. The left central incisor showed a root fracture in the cervical region and the right central incisor had an extensive external root resorption. The left lateral incisor presented endodontic treatment (Fig. 2).

She was diagnosed with a Class II division 1 malocclusion with lip incompetence. The main objectives of the orthodontic treatment plan were to eliminate protrusion of the superior teeth and establish stable occlusion with acceptable anterior dental esthetics.

Two treatment options were considered. The first option was to extract two maxillary premolars and both ankylosed central incisors replacing them by a fixed or removable prosthesis until her facial growth was completed. Then a restorative treatment with implants would be considered. The case would finish in Angle Class II and the young patient would use a temporary prosthesis in an extremely esthetic region until her skeletal growth has ended. The second option was to extract the central incisors only and pulling the lateral incisors to the central incisor position, restoring them to improve esthetics, and the treatment would finish in Angle Class II. This option seemed to be the most acceptable for the orthodontist, the patient and her parents.

The treatment started by installing a removable appliance in the superior arch (Fig. 3). This device had the following purposes:

1. Preserve the patient aesthetics after the extractions of the central incisors (two artificial teeth were added to the appliance) (Fig. 3). There was a significant gain in patient self-esteem considering that her natural teeth were projected and darkened due to endodontic treatment.

2. Improve the overbite, incorporating a stop bite into the removable orthodontic appliance.

3. Start the approach of lateral incisors with caution by means of springs added in the removable appliance. The artificial teeth were gradually reduced proximally allowing movement of the lateral incisors without harming the aesthetics of the patient.

A fixed appliance was installed in the mandibular arch initially for Tandem mechanics in molars. We opted for this mechanics to increase space in the mandibular arch and simultaneously to lose maxillary anchorage through the use of elastic Class III. After this stage brackets on incisors, canines and mandibular premolars were bonded and treatment was accomplished with conventional mechanics. Fixed appliance was installed in the maxillary arch. The final space closure was performed with intramaxillary elastic chain and with a sequence of arch wires leaving a well distributed interproximal space to be filled by composite restorations.

During all treatment the patient underwent radiographic monitoring to verify parallelism and pulp vitality of the lateral incisors. The right lateral incisors needed endodontic treatment during orthodontic treatment (Fig. 2).

After orthodontic treatment the appliances were removed and the patient was referred to restorative treatment. Direct composite restorations were made in the lateral incisors to mimic central incisors. Enamelplasty was done in the canines to transform them in lateral incisors. The patient and her parents were pleased with the treatment outcome (Fig. 4).

The case was satisfactorily completed solving the problem of lost central incisors without the use of prosthesis. This fact is more relevant when considering the young age of the patient. 

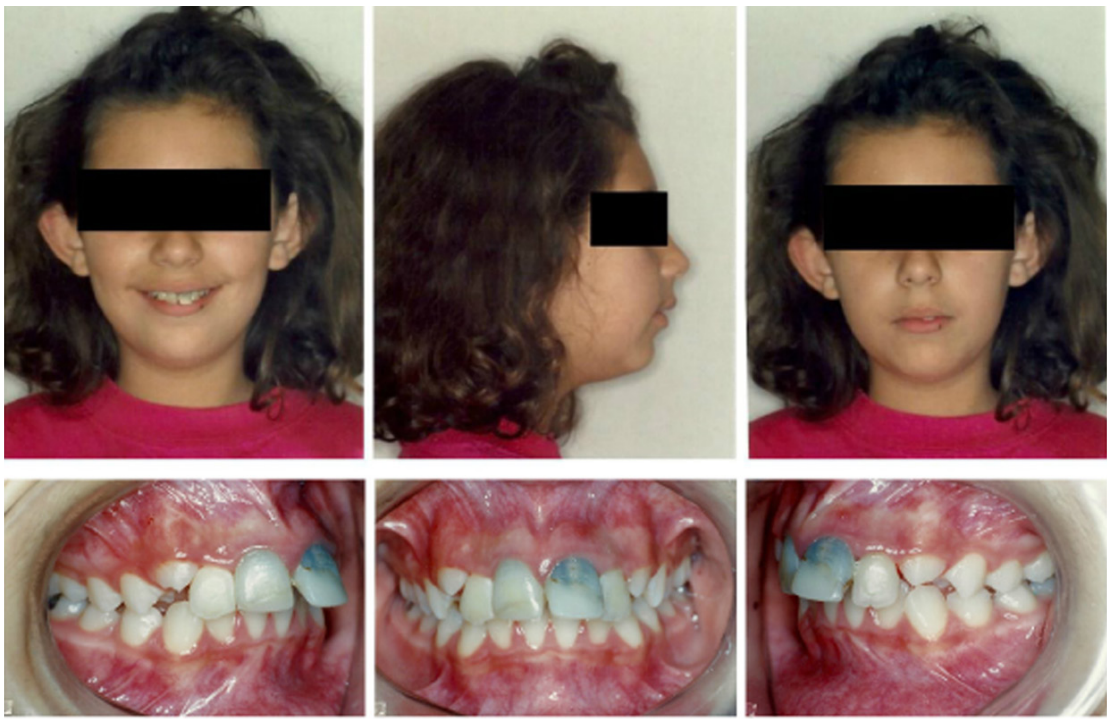

Fig 1. Pretreatment facial and intraoral photographs.
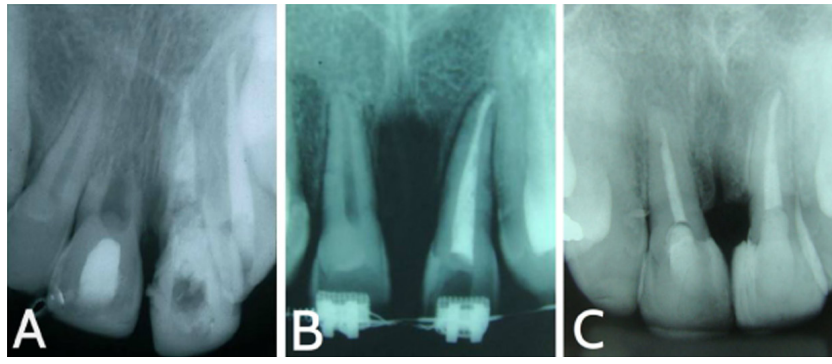

Fig 2. Initial radiograph (A); During orthodontic treatment radiograph (B); Post treatment radiograph: lateral incisors with temporary composite restorations (C).
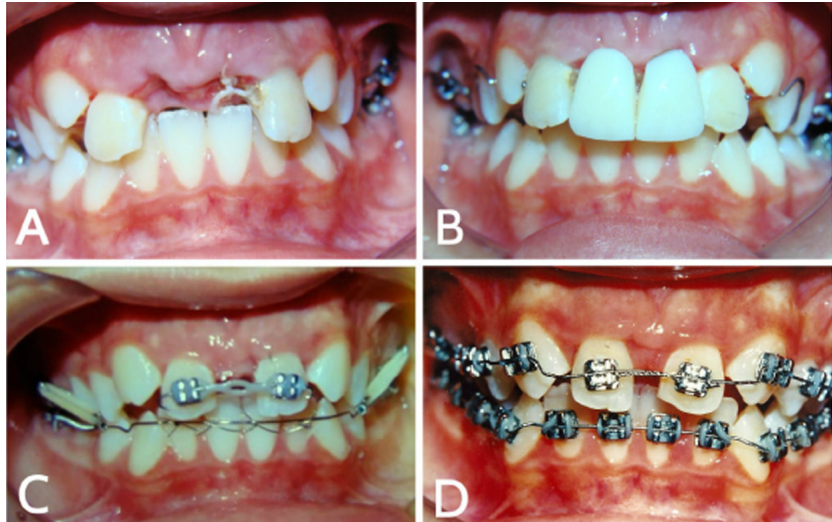

Fig 3. Post central incisors extraction aspect $(A)$; Removable appliance with artificial central incisors in position (B); Tandem mechanics and space closure between lateral incisors with chain elastics (C); Fixed appliances in both arches (D).
Fig. 4. Post treatment facial and intraoral photographs.
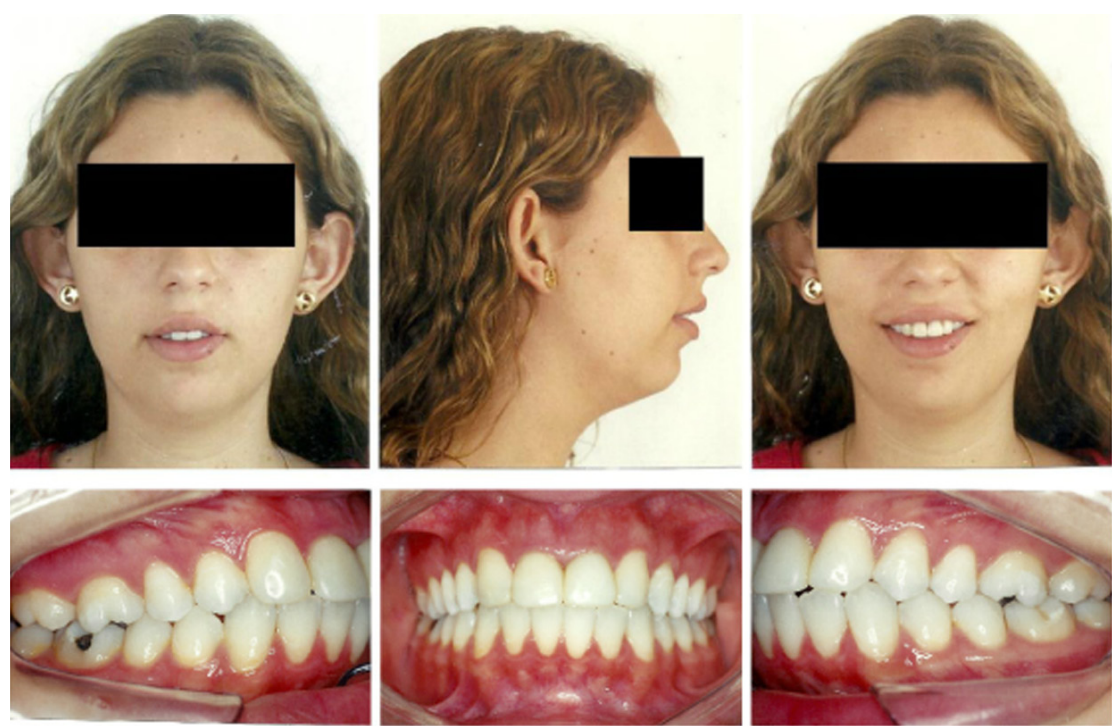


\section{Discussion}

Dental injuries confront dental practitioners quite often (1-4). The incisors are the most common injured teeth and bicycle accidents are often involved (2). Children with a $6 \mathrm{~mm}$ or higher overjet had four times higher risk of suffering dentoalveolar trauma, compared with those with lower overjet (5). An Angle class II malocclusion is traditionally treated orthodontically with extractions of premolars. However this patient also had protruded, traumatized and ankylosed central incisors, which compromised esthetics and function. In this case we opted for extraction of central incisors and pulled the lateral incisors to the extraction sites.

The treatment of a young patient with a dental prosthesis in aesthetic region until finalization of growth may not be the best option because of the bad impact of dental injuries on quality of life, especially for young girls $(6,7)$. There were no extractions in the mandibular arch because this could increase the convex profile of the patient. The dental crowding was corrected by means of dental interproximal stripping and Tandem mechanics. Although she had lateral incisors with a large mesiodistal distance $(8 \mathrm{~mm})$, we opted for the restorative treatment to improve esthetics and hide the discoloration of the lateral incisors crowns due to endodontic treatment. This unconventional treatment plan requires specific teeth placement so they could be restored and reshaped $(4,8)$. Extensive dental grinding can be performed without significant discomfort, and with minor or no pulp and dentin reactions (9). The canines were trimmed in the palatal side to avoid interference with the mandibular incisors. The labial side was flattened and the cuspids were reduced $2 \mathrm{~mm}$ in both canines.

Canine-protected occlusion is not feasible when the canine is replaced by the premolar (8). As a result, forces generated through lateral excursive movements are placed on the smaller and thinner roots of the first premolar (10). However long-term periodontal and occlusal studies on congenitally missing lateral incisors have shown that orthodontic space closure with premolar substitution of canines was periodontally preferable to prosthetic replacement of the missing lateral incisor $(8,11)$.

Extraction of the maxillary central incisors is not a usual treatment protocol. However, in patients with traumatized and ankylosed central incisors and Class II division 1 malocclusion, this might be a good alternative to preserve tooth structure and eliminate patient's dependence of a permanent prosthesis. Nevertheless, additional cosmetic finishing might be necessary. 2003; 19:67-71.

2. Kahabuka FK, Mugonzibwa EA. Risk factors for injuries to maxillary permanent incisors and upper lip among schoolchildren in Dares Salaam, Tanzania. Int J Paediatr Dent 2009;19:148-54.

3. Hecova $H$, Tzigkounakis $V$, Merglova $V$, Netolicky J. A retrospective study of 889 injured permanent teeth. Dent Traumatol 2010;26:466-75.

4. Sabri R. Treatment of a Class I crowded malocclusion with an akylosed maxillary central incisor. Am J orthod dentofacacial Orthop 2002;122:557-65.

5. Schatz JP, Hakeberg M, Ostini E, Kiliaridis S. Prevalence of traumatic injuries to permanent dentition and its association with overiet in a Swiss child population. Dent Traumatol 2012, May 24. doi: 10.1111/j.1600-9657.2012.01150.x.

6. Aldrigui JM, Abanto J, Carvalho TS, Mendes FM, Wanderley MT, Bönecker M, et al. Impact of traumatic dental injuries and malocclusions on quality of life of young children. Health Qual Life Outcomes $2011 ; 24,9: 78$.

7. Traebert J, de Lacerda JT, Foster Page LA, Thomson WM, Bortoluzzi MC. Impact of traumatic dental injurieson the quality of life of schoolchildren. Dental Traumatology 2012; doi: 10.1111/j.1600-9657.2012.01114.x

8. Janson G, Valarelli DP, Valarelli FP, Freitas MR, Pinzan A. Atypical extraction of maxillary central incisors. Am J Orthod Dentofacial Orthop 2010;138:510-7.

9. Zachrisson BU, Mior IA. Remodeling of teeth by grinding. Am J Orthod Dentofacial Orthop 1975;68:545-53.

10. Tuverson DL. Orthodontic treatment using canines in place of missing maxillary lateral incisors. Am J Orthod Dentofacial Orthop 1970; 58:109-27.

11. Senty El. The maxillary cuspid and missing lateral incisors: esthetics and occlusion. Angle Orthod 1976;46:365-71. 